\title{
Generation of monodisperse aerosols through condensation nuclei control
}

\author{
H. M. Kadlimatti ${ }^{1}$, S. Gangamma ${ }^{2}$ \& S. K. Varghese $^{3}$ \\ ${ }^{1}$ Department of Mechanical Engineering, \\ Basaveshwar Engineering College, Bagalkot, India \\ ${ }^{2}$ Department of Chemical Engineering, National Institute of Technology, \\ Karnataka, Surathkal, India \\ ${ }^{3}$ Departmant of Civil Engineering, National Institute of Technology, \\ Karnataka, Surathkal, India
}

\begin{abstract}
A device for the generation of monodisperse aerosols through condensation nuclei control has been designed and tested in the present study. A continuous flow, evaporation-condensation aerosol generator has been designed to produce monodisperse aerosols of low vapor pressure organic liquids, such as dioctyl phthalate (DOP), at flow rates over $2.5 \mathrm{lpm}$. Nebulised $\mathrm{NaCl}$ particles are passed through the particle number controller to reduce the number concentration close to $10^{5}$ / cc to suppress homogeneous condensation. The condensation nuclei with nitrogen as a carrier gas are passed through a bubbler containing DOP, producing a nuclei-vapor mixture. The mixture is condensed producing the aerosols of narrow size distribution. A heater section previous to the condenser section provides complete evaporation across the tube diameter, while the condenser walls in free convection create a low temperature gradient, both of which enhance aerosol monodispersity. The results show that controlling the nuclei number concentration as well as vapor source can produce aerosols with sufficient monodispersity.
\end{abstract}

Keywords: condensation nuclei, evaporation, condensation, monodisperse aerosol. 


\section{Introduction}

An important element of aerosol technology is the production of test aerosols for calibrating instruments, conducting aerosol research, developing and testing air cleaning and air sampling equipment. Monodisperse aerosols are used to calibrate particle size measuring instruments and to determine the effect of particle size on sampling devices. A monodisperse aerosol is usually defined as an aerosol that has a geometric deviation of less than 1.2. In aerosol research, monodisperse test aerosols of known size, shape and density are highly desirable because most aerosol properties depend strongly on particle size, which is best controlled by using monodisperse aerosols. Tests made with a series of monodisperse aerosols, each having a different particle size, permit the evaluation of the effect of particle size on aerosol properties or the performance of an instrument. Test aerosols also used for various types of inhalation studies, such as studies of animal exposure to toxic substances, respiratory deposition in humans or animals and the administration of therapeutic aerosols [3].

Understanding the fundamental mechanisms of aerosol nucleation and growth has long been a central problem in aerosol science. Such understanding has important implications in characterizing and controlling fine particle emissions from combustion systems and in elucidating the dynamic processes governing the formation and growth of atmospheric aerosols. In simulating atmospheric aerosol dynamics, for example, it is desired to predict the rate of new particle formation as a function of the rate of generation of condensable vapor by gasphase chemical reactions. Predicting rates of new particle formation in the atmosphere requires consideration of the effect of both preexisting particles and newly formed growing particles on the vapor and cluster concentrations in the system Simultaneous homogeneous nucleation [5].

Sinclair and La Mer [8] first described the generation of aerosols by controlled condensation of vapour upon nuclei. Di-2-ethylhexyl sebacate (DEHS), an organic liquid with a low vapour pressure at room temperature acts as aerosol substance. Since DEHS is insoluble in water and known as non-toxic, its aerosols can be inhaled by a human being and used for deposition studies of particulate matter in the human respiratory tract

Aerosols with particle sizes below $10 \mu \mathrm{m}$ may be generated by condensation. A stream of nuclei is exposed to the vapour of a low-volatile liquid at an elevated temperature, and the controlled heterogeneous condensation of the vapour onto the nuclei results in the formation of the product aerosol [2].

For particle sizes down to $0.1 \mu \mathrm{m}$ the use of aerosol generators of the La MerSinclair type provides monodisperse aerosols. Other types of condensation aerosol generators were used by many authors to generate aerosols with particle sizes below $0.1 \mu \mathrm{m}$ But most of this system--heated wire generator exploded wire generator high intensity arc generator plasma torch generate polydisperse or low concentrated quasimonodisperse aerosols with decreasing concentrations with time.

The use of electrically heated tube furnaces to vapourize the aerosol material show the possibility of the generation of highly concentrated aerosols by means 
of homogeneous condensation. The particle sizes range down to $1 \mathrm{~nm}$ with long time stability but with size distributions with geometric standard deviations of $\sigma_{\mathrm{g}}$ $\lesssim 2.5$ i.e. polydisperse aerosols.

Monodisperse aerosols are obtained after electrostatic classification. The high concentrations and the relative small size distributions of the primary condensation aerosols provide classified monodisperse aerosols with concentrations between $10^{3}$ and $10^{6}$ particles $/ \mathrm{cm}^{3}$ for particle diameters down to $2 \mathrm{~nm}[7]$.

For some applications, such as instrument calibration, a monodisperse aerosol is desired. There is however no precise definition of a monodisperse aerosol, i.e. how small a spread of particle sizes constitutes "monodisperse". As most generated aerosols have a lognormal distribution, the geometric standard deviation, $\sigma_{\mathrm{g}}$, can be used as a measure of the monodispersity. That is, an aerosol, which has $\sigma_{\mathrm{g}}$ less than about 1.22 , could be assumed monodisperse. This arbitrary definition has no rigorous justification, but can be used as a rough indicator. Most so-called monodisperse aerosol generators can produce aerosols with $\sigma_{\mathrm{g}}<1.1[6]$.

Milos et al, [4] have described a generator for producing monodisperse aerosols. The process involves atomizing the aerosol material (dioctyl phthalate was used) to form a polydisperse aerosol, which is rendered uniform by vaporization and condensation. The principle is similar to that used by Rapport and Weinstock and by Preining [4], but it has been found that by extracting a small percentage of the aerosol from the center of the stream from the condensing tube, a more monodisperse aerosol could be obtained. It is also found that dissolving the DOP in alcohol and could easily vary the size of the DOP aerosol by varying the solution concentration. Thus, with DOP concentration ranging from 0.001 to 100 per cent the size of the DOP aerosol could be varied from $0.036 \mu \mathrm{m}$ to $1.3 \mu \mathrm{m}$ dia.

The device developed for the generation of monodisperse aerosols can be used for the study of air pollution effects at the laboratory level, as the effect of aerosol is size dependent.

\section{Experimental setup}

The experimental setup used for the production of monodisperse aerosol by evaporation - the condensation process is shown in figure 1. Using the nebuliser, a very dilute $\mathrm{NaCl}$ solution is sprayed from a nozzle to produce droplets. Upstream of the nebuliser, a diffusion dryer removes the water from the droplets to produce small crystals, depending on the original concentration of the solution. The particle number controller permits lowering of the concentration of the salt crystals from the original value, before the crystals are used as condensation nuclei in a heterogeneous condensation process. Since the concentration of the final aerosol is approximately same as concentration of the nuclei aerosol, the particle number controller can be used to control the aerosol concentration within the boundaries imposed by the heterogeneous condensation 
process. The size of the aerosol particles is determined by the quantity of available vapor per nucleus. The number concentration of the nuclei is set by the flows in the particle number controller.

The saturation of the gas, with vapor from the aerosol material, takes place in the bubbler. The nuclei aerosol bubble through the aerosol material at a constant temperature. Depending on temperature and vapor pressure, a certain saturation concentration of the vapor is achieved in the bubbler. The bypass around the saturator allows dilution of the saturated gas. This permits rapid adjustment of particle size by changing the ratio of bypass to total flow rate, rather than by waiting to heat or cool the saturator.

The nuclei-vapor mixture is re-heated, in the reheater section, to ensure that no condensation takes place upstream of the condensation chimney. In the condensation section, the vapor-nuclei mixture is cooled down in a laminar flow and the resulting supersaturation causes the vapor to condense onto the nuclei.

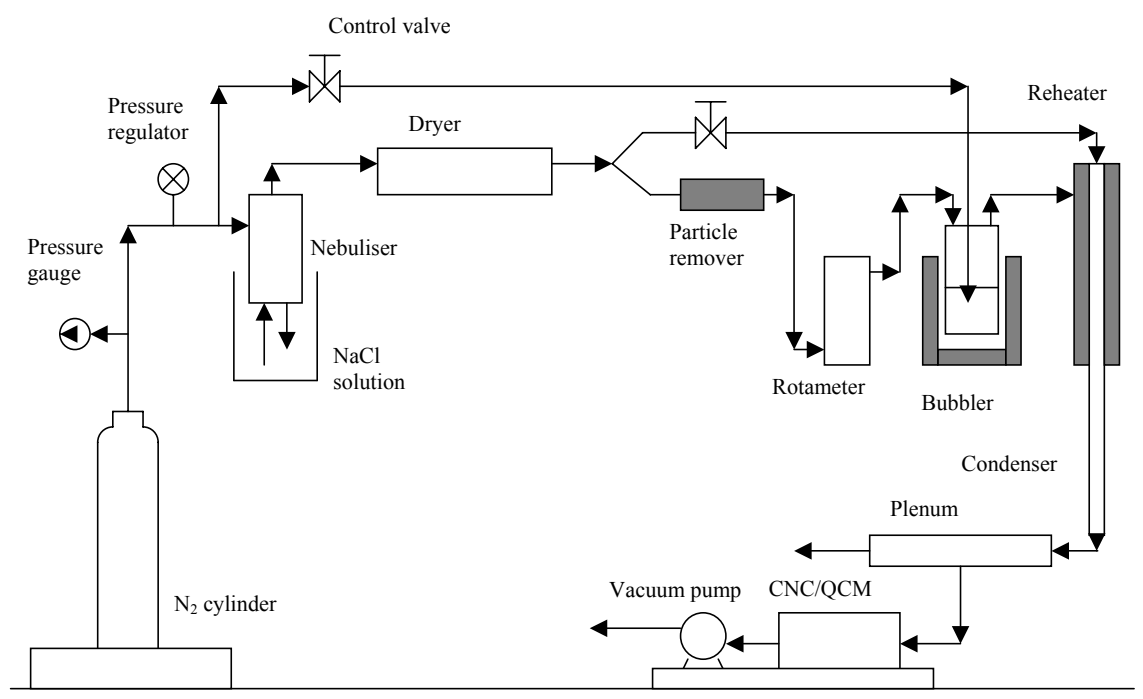

Figure 1: $\quad$ Experimental setup to generate monodisperse aerosols.

\subsection{Aerosol measurement technique}

Size segregated particulate mass was measured by cascade impactor with Quartz Crystal Microbalance (PC-2 QCM, California Measurements, INC, USA). The sampling flow rate is $1.5 \mathrm{lpm}$. The impactor has ten stages and segregates aerosol samples into ten size ranges between 25 and $0.05 \mu \mathrm{m}$. The manufacturer reported the cut sizes for the impactor for spherical particle of density $2 \mathrm{gcm}^{-3}$. However, these cut diameters are different from the values reported in the calibration studies on the instrument [1]. In this study, the cut sizes of the impactor were adopted from Horton et al. [2]. The performances of the crystals were stable and satisfactory for the aerosols generated by aerosol generator. The aerosol concentrations observed on stages having cut sizes greater than $3.1 \mu \mathrm{m}$ were very 
low and found to be statistically unreliable. Therefore, only the mass measured by stages having cut sizes less than $3.1 \mu \mathrm{m}$ are used in our assessment.

\section{Results and discussion}

The control over the number concentration of condensation nuclei close to $10^{5} / \mathrm{cc}$ is achieved with the help of particle remover. It is clear from the table 1 that, the diffusion battery is having very less collection efficiency compared to the particle remover which is having a collection efficiency of $71.42 \%(12 \mathrm{mg} / \mathrm{l}$ and $24 \mathrm{mg} / \mathrm{l})$ with steel wool of diameter $0.15 \mathrm{~mm}$ and $91.42 \%(12 \mathrm{mg} / \mathrm{l}$ and $24 \mathrm{mg} / \mathrm{l})$ with plastic fiber of diameter $0.14 \mathrm{~mm}$. Since the particle remover with plastic fiber is having higher collection efficiency compared to the diffusion battery and the steel wool, particle remover with plastic fiber is used throughout the experiment

The size distribution of the initial $\mathrm{NaCl}$ nuclei measured after passing through dryer is shown in figure 2. The initial $\mathrm{NaCl}$ nuclei have a MMD of $0.26 \mu \mathrm{m}$ and probably number distribution peaks. This is ideal for generating particles in the sub micron range. The low vapor pressure liquid, DOP is then vaporized and condensed over the $\mathrm{NaCl}$ nuclei in the condenser section of the experimental setup. The size of the $\mathrm{NaCl}$ is increased due to the condensation process and is shown in the figure 3 . The monodispersity is achieved by controlling the flow condition in the condenser tube.

Table 1: $\quad$ Condensation nuclei number concentration.

\section{NaCl Concentration: $12 \mathrm{mg} / \mathrm{litre}$}

\begin{tabular}{|c|c|c|c|c|c|}
\hline \multirow{3}{*}{$\begin{array}{l}\text { Pressure } \\
\left(\mathrm{kg} / \mathrm{cm}^{2}\right)\end{array}$} & \multirow{3}{*}{$\begin{array}{c}\text { Flow } \\
\text { rate } \\
(\mathrm{lpm})\end{array}$} & \multirow{3}{*}{$\begin{array}{c}\text { Value } \\
\text { position }\end{array}$} & \multicolumn{3}{|c|}{ Number concentration per cc } \\
\hline & & & \multirow{2}{*}{$\begin{array}{c}\begin{array}{c}\text { Diffusion } \\
\text { battery }\end{array} \\
1000 \text { tubes } \\
(1 \mathrm{~mm} \\
\text { diameter })\end{array}$} & \multicolumn{2}{|c|}{ Particle remover } \\
\hline & & & & $\begin{array}{c}\text { Steel wool } \\
(0.15 \mathrm{~mm} \\
\text { diameter })\end{array}$ & $\begin{array}{c}\text { Plastic } \\
\text { fiber } \\
(0.14 \mathrm{~mm} \\
\text { diameter })\end{array}$ \\
\hline 1.8 & 1.5 & $\begin{array}{c}\text { Closed } \\
\text { Opened }\end{array}$ & $\begin{array}{l}5 \times 10^{5} \\
7 \times 10^{5}\end{array}$ & $\begin{array}{l}2 \times 10^{5} \\
7 \times 10^{5}\end{array}$ & $\begin{array}{l}6 \times 10^{4} \\
7 \times 10^{5}\end{array}$ \\
\hline
\end{tabular}

NaCl Concentration: 24 mg/litre

\begin{tabular}{|c|c|c|c|c|}
\hline \multirow{3}{*}{$\begin{array}{l}\text { Pressure } \\
\left(\mathrm{kg} / \mathrm{cm}^{2}\right)\end{array}$} & \multirow{3}{*}{$\begin{array}{l}\text { Flow } \\
\text { rate } \\
(1 \mathrm{pm})\end{array}$} & \multirow{3}{*}{$\begin{array}{c}\text { Value } \\
\text { position }\end{array}$} & \multirow{2}{*}{\multicolumn{2}{|c|}{$\frac{\text { Number concentration per cc }}{\text { Particle remover }}$}} \\
\hline & & & & \\
\hline & & & \multirow{2}{*}{$\begin{array}{c}\text { Steel wool } \\
(0.15 \mathrm{~mm} \\
\text { diameter) } \\
2 \times 10^{5} \\
7 \times 10^{5}\end{array}$} & $\begin{array}{c}\text { Plastic fiber } \\
(0.14 \mathrm{~mm} \text { diameter })\end{array}$ \\
\hline 1.8 & 1.5 & $\begin{array}{c}\text { Closed } \\
\text { Opened }\end{array}$ & & $\begin{array}{l}6 \times 10^{4} \\
7 \times 10^{5}\end{array}$ \\
\hline
\end{tabular}




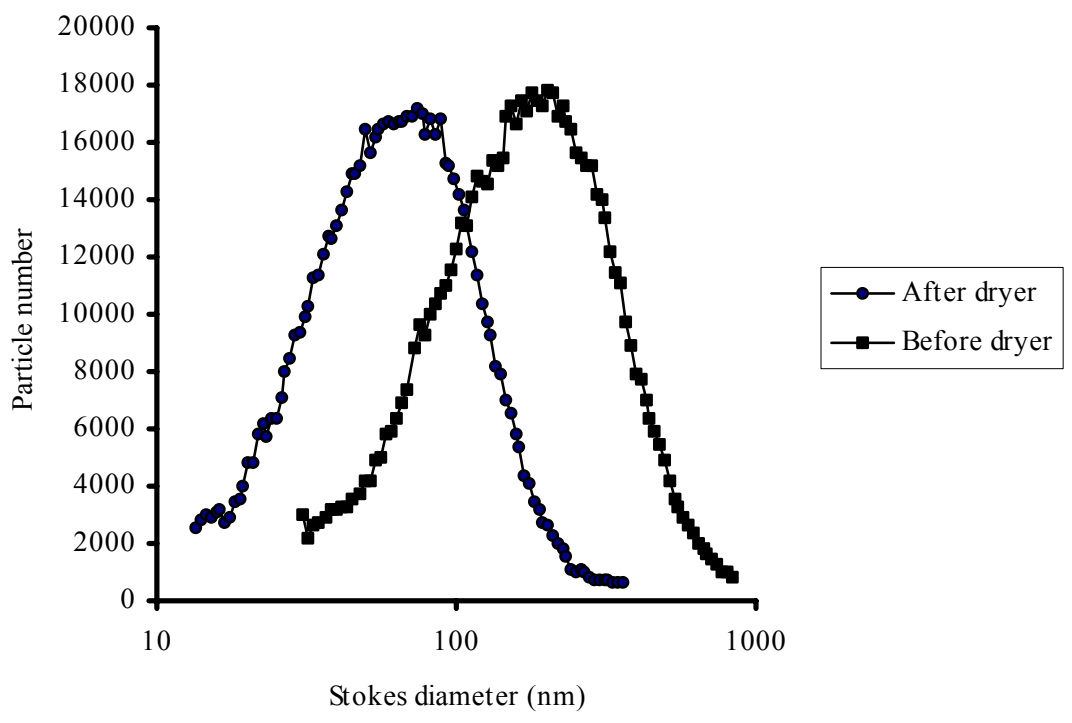

Figure 2: $\quad$ Particle size before and after dryer.
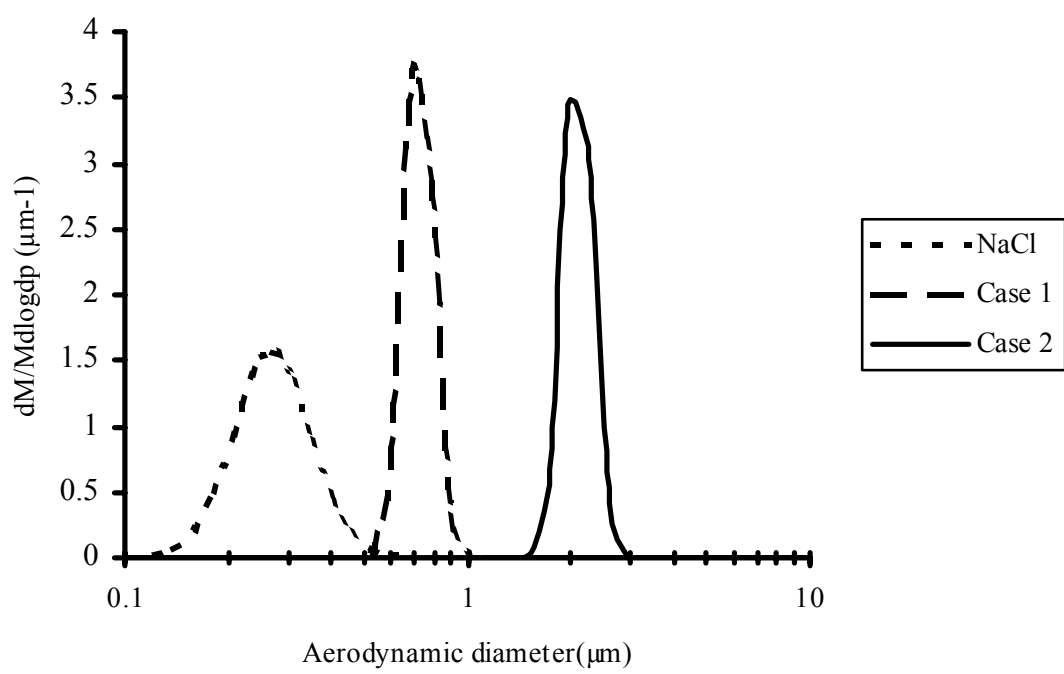

Figure 3: Mass size distributions of initial $\mathrm{NaCl}$ nuclei and aerosols after condensation of DOP vapour.

For case 2 the temperature of the bubbler is $200{ }^{\circ} \mathrm{C}$ and flow rate through the bubbler is $1.5 \mathrm{lpm}$, whereas for case 1 the temperature of the bubbler is $150{ }^{\circ} \mathrm{C}$ and the bubbler flow is $1.5 \mathrm{lpm}$ with the operating pressure $1.8 \mathrm{~kg} / \mathrm{cm}^{2}$. The 
increased bubbler temperature generated more vapor available for condensation with same number of nuclei, hence caused the increase in diameter compared to case 1 . The both cases showed good monodispersity but the study is limited by the size resolution of the instrument used in the experiment. The results obtained are comparable with the results of Horton et al. [2].

\section{References}

[1] Fairchild C.I. and Wheat L.D. (1984). Calibration and evaluation of a real time cascade impactor. Am.Ind.Hyg.Assoc.Journal, 45(4), pp.205-211.

[2] Horton, K. D., Mitchell, J. P. and Nichols, A. L. Characterization of condensation type aerosol generator. J. Aerosol Sci. 22(3), pp. 347-363, 1991.

[3] Hinds W.C. Aerosol Technology (Chapter 21), John Wiley. Inc, New York, pp. 428-446, 1999.

[4] Milos T. B., Liu Y. H. Liu and Whitby K.T. Evaluation of the condensation aerosol generator for producing monodispersed aerosols. J. Aerosol Sci., 2, pp.39-46, 1971.

[5] Pesthy A. J., Flagan R. C., and Seinfeld J. H. Theory of Aerosol Formation and growth in laminar flow. Journal of Colloid and Interface Science, 9(2), pp.525-545, 1983

[6] Ristovski Z.D., Morawska L. and Bofinger N.D. Investigation of a modified Sinclair-La Mer aerosol generator in the submicrometer range. J. Aerosol Sci., 29(7), pp.799-809, 1998.

[7] Scheibel H.G. and Porstendorfer J. Generation of monodisperse Ag- and Nac1- aerosols with particle diameters between 2 and $300 \mathrm{~nm}$. J. Aerosol Sci., 14(2), pp. 113-126, 1983.

[8] Stahlhofen W. Gebhart J. Heyder J. and Roth C. Generation and properties of a condensation aerosol of di-2-ethylhexyl sebacate (DEHS). J. Aerosol Science. 6, pp.161-167, 1975 